\title{
RECENT ADVANCES IN B.C.G. VACCINATION
}

By K. Neville Irvine, D.M.Oxon.

Adviser in B.C.G. Vaccination to the Oxford Regional Hospital Board

The history of B.C.G. up to 1948 has been dealt with elsewhere (Irvine, 1949); an article in this Journal covered the years I949-5 I (Irvine, I952): this paper is intended to summarize the work that has been carried out in the years 1952-54.

\section{Safety}

For the first time two cases of progressive tuberculosis resulting from B.C.G. vaccination have been reported. The first was a seven-yearold Danish boy who was given B.C.G. intracutaneously in a batch of 30 children; the vaccinations ran a normal course in the other 29. This boy began to ail within two weeks of vaccination and became progressively worse; he eventually died after two years from cachexia with generalized tuberculosis. An organism identified as B.C.G. was grown from the lungs, liver, spleen, kidneys and mesenteric glands; none of the laboratory animals inoculated developed progressive tuberculosis (Meyer, 1954). The second was a Norwegian youth, aged I9, who was vaccinated intracutaneously in 1948: in 1949 he developed a glandular abscess and in I950 an abscess of the chest wall from which 'tubercle bacilli of the B.C.G. type' were grown: despite chemotherapy he developed a lung infiltration in 1951 and caries in a rib and clavicle: in 1952 a cavity was found in the right kidney and spinal caries with paraplegia developed: in 1953 emaciation became extreme and he died. At autopsy a generalized infection with an organism identified as B.C.G. was found; none of the many animals inoculated developed progressive tuberculosis (Thrap-Meyer, 1954). In neither of these cases was any increase in the virulence of B.C.G. found: both boys must have had a complete absence of resistance to any tubercle bacillus and would presumably have succumbed rapidly to a virulent infection.

This brings the number of deaths resulting from B.C.G. vaccination up to three; the third case (Despierres et al., 195I) was reported in the previous article. As over a hundred million persons have now been given B.C.G. (Saenz et al.,
1954), these three deaths, though disturbing, d $\vec{\theta}$ not materially affect the safety of the vaccines, vaccination against smallpox, which is regard as a safe and desirable procedure, caused deaths in the period 1940-49 in England and Wales alone (Registrar-General, 1949).

\section{Efficacy}

Little fresh light has been thrown on this problem during the last three years. No repost of the M.R.C. trial on school children has yet been published. Olsen (1953) has reported further decline of tuberculosis in the island $\frac{0}{4}$ Bornholm and described the protection given bo B.C.G. vaccination in a small epidemic outbefes of tuberculosis. The Final Report of the International Tuberculosis Campaign (I records the vaccination of nearly 17 milfow persons, but gives little statistical informatio Sams (1954) reports nearly 53 million vaccination between 1945 and $195^{2}$ on Japanese under the age of 30 ; the tuberculosis mortality rate in Japa fell from 282.2 per hundred thousand in I945 82.1 in 1952 and practically the whole of the dro occurred in this under-thirty age-group.

\section{Present Policy}

Now that the vaccination of nurses, medic students and contacts is being routinely carried out in this country, the Ministry has released B.C.C. for use on thirteen-year-old school children. This is a broadening of the original policy of vaccinating only those individuals who are specially exposed to infection, to include a complete age-group that is entering a period of life when the risk of tubercin losis is high. The advantage of selecting this particular age is that most children will be undep observation for some months before leaving school; the disadvantage is that part of the periog of protection will be wasted before the child goes out into the world.

This extension to school children may meant nearly half a million additional vaccinations a yearr This is beyond the capabilities of the ove? worked Chest Physician, and Medical Officers of 
Health are already training School Medical Officers as vaccinators. The original five sessions, with two prevaccination and one postvaccination test, are cumbersome for such numbers and attempts are being made to simplify the procedure.

\section{Tuberculin Testing}

For nurses, medical students, and contacts, the Ministry has supplied dilutions of Old Tuberculin for Mantoux testing: for school children, dilutions of P.P.D. are being issued. Up to the present it has been thought that dilutions of O.T. and P.P.D. ran mathematically parallel, but Seibert and DuFour (1954) have shown that the first strength P.P.D. (0.00002 mg.) is more sensitive than its official equivalent in O.T. (I/10,000) and the second strength P.P.D. ( $0.005 \mathrm{mg}$.) is less sensitive than its equivalent $\mathrm{I} / 40 \mathrm{O}$. T. If this is confirmed there will have to be some readjustment of standards.

In its earlier campaigns the I.T.C. attempted to use two prevaccination tuberculin tests; it soon became apparent that this was impracticable. An attempt was then made to use a single Mantoux Io T.U., but too many fierce reactions resulted in some countries. A Mantoux 5 T.U. was finally chosen as the universal standard pre- and postvaccination I.T.C. test. This may be an adequate prevaccination test to exclude active tuberculosis, but it is inadequate for detection of the weak postvaccination allergy; the Ministry of Health (1953) recommends a Mantoux ro T.U. for this country. In the Oxford Region, where research into the duration of allergy is being carried out, all persons are still tested to a Mantoux Ioo T.U. so that a similar test may justifiably be used at their followup. This is admittedly open to the criticism that some persons who should have been vaccinated may have been excluded by a non-specific or pseudo-reaction to this strength; the work of Bates et al., (I95I) and Edwards and Palmer (I953), show that in some tropical countries this nonspecific factor is so prevalent that the roo T.U. is quite unreliable. Whether these pseudoreactions are due to the presence of some saprophyte has not yet been demonstrated, but Zettergren et al., (1952), have found a mycobacterium balnearea in swimming pools, infection with which will produce a positive tuberculin reaction in man. There is, however, no evidence to suggest that non-specific reactions to a Mantoux IO० T.U. are common in this country:'

Clearly some ' one-shot' prevaccination test is highly desirable. Unless non-specific reactions are found to be common in this country, there is no reason why a test of the sensitivity of a Mantoux 100 T.U. should not be used; the use of the Mantoux 100 T.U. itself as a one-shot test is precluded by the fact that severe reactions would occur in sensitive persons. The original Pirquet test and its modification, the Adrenalin-Pirquet, are only of about equal sensitivity to the Mantoux ro T.U. The reliability of the jelly test and its flourpaper modification introduced by Dick (1950) is upheld by Lendrum (1951), but more recently doubt has been thrown on it by Coles (1952), Frew et al., (1953), and Caplin et al., (1954); in any case its use is restricted to children.

A new tuberculin test has recently been devised by Heaf (195I), which gives promise of being the ideal one-shot test. The test is performed with a special instrument which automatically stabs six needles into the skin to a standard depth through a film of adrenalinized O.T.; P.P.D. $2 \mathrm{mg} . / \mathrm{ml}$. in 25 per cent. glycerine (without adrenalin) may also be used (Heaf, 1953). The reaction, which is read on the third day, varies from a small papule at the site of each puncture up to a solid plaque of induration. Its sensitivity appears to be only a little less than that of the Mantoux roo T.U. (Irvine, 1955); but it may safely be given without a preliminary test; the worst reaction I have seen was an induration of $30 \mathrm{~mm}$. in diameter with six discrete $3 \mathrm{~mm}$. vesicles over the puncture marks. No skill is required to give this test as the Heaf ' gun' is automatic. As the reaction fade? slowly it may be found possible to read it at sever. days; this would form a useful 'market day test for country chest clinics where the test could be given and read at the weekly clinic which is usually held on market days.

Though Foley and Parrot (1953) still defend their practice of vaccinating without tuberculin testing, it is generally agreed that a prevaccination test is essential, but there is considerable argument as to whether the postvaccination test could not be omitted. In the first 5,000 persons of all ages vaccinated in the Oxford Region a conversion rate of 99.9 per cent. was found; in view of this is the time and expense involved in conversion testing warranted? For school children the answer would appear to be 'No,' provided that a high conversion rate is confirmed in this age-group the M.Os.H. in the Oxford Region are working together as a voluntary research team to test this statistically. On the other hand for nurses and medical students, who are bound to come in contact with open tuberculosis, there can be no justification for omitting to check that each individual has converted.

\section{Variations in the Vaccine}

Pierce and Dubos (1954) have shown that there is considerable variation between the fresh vaccines produced at different centres. Edwards and Palmer (1953) have demonstrated that 
exposure to direct tropical sunlight will kill fresh B.C.G. in half an hour; at the latitude of Great Britain it would take an hour. Even if shaded from direct sunlight, the glare from a tropical sky has a similar effect in four hours. Room temperature has little deleterious effect on fresh B.C.G. provided it does not reach $20^{\circ} \mathrm{C}$. $\left(68^{\circ} \mathrm{F}\right.$.); rapid deterioration occurs at $30^{\circ} \mathrm{C}$. $\left(86^{\circ} \mathrm{F}\right.$.). Other interesting findings are reported in this W.H.O. monograph.

The variation between the freeze-dried vaccines produced at different centres is so great that W.H.O. (1954) has as yet been unable to recommend their general use. As van Deinse (195I) points out, up to 95 per cent. of the organisms are destroyed during the process of freeze-drying by some of the methods used.

\section{B.C.G. Vaccination}

New books on this subject have been produced by Griesbach (1954), Irvine (1954) and Mande (1954). Intracutaneous vaccination still remains the method of choice; in this country there is no option, as the vaccine supplied by the Ministry is only suitable for this purpose. The public are becoming used to the weeping local lesion which is its main disadvantage, while the advantages of this method are becoming more apparent to the medical world. Though multiple-puncture usually leaves no scar, when it does the result is a white rosette $I \frac{1}{2}$ in. in diameter which enlarges as the infant grows. After scarification the site must be left untouched to dry for 15 minutes, which raises difficulties of organization in children's clinics; the subsequent duration of allergy appears to be shorter than with the intracutaneous method.

De Assis's (1953) ' concomitant' oral vaccination in Brazil has attracted much notice recently. Six doses of $100 \mathrm{mg}$. B.C.G. are given by mouth at monthly intervals from birth; for older infants the dose is doubled. Conversion is said to take place usually about the eleventh week, but the subsequent doses may completely desensitize the infant so that at the end of six months it has reverted to negative. It is claimed that this desensitization to a state of 'iathergy' is accompanied by further increase in resistance; this is in accord with Birkhaug's work on guineapigs (1940). De Assis has followed this theory to its logical conclusion and produced iathergy in natural positive reactors by oral B.C.G.; he claims that this increases their resistance. Latterly he has dispensed with all prevaccination tuberculin testing and gives these repeated oral doses indiscriminately to all children; no ill effect other than a transitory gastro-intestinal upset has been reported.
W.H.O. (I954) has pointed out that all strains气 of B.C.G. are not equally suitable for this pro- $\frac{3}{8}$ cedure. When oral B.C.G. was tried in the Netherlands on 1,814 infants, the results were. disastrous; cervical adenitis occurred in 64 cases -half of which ultimately suppurated-and chronic middle ear infection occurred in 19 case 5 from 7 of which B.C.G. was grown (Hammelburg 1953).

The discovery that B.C.G. vaccination produces a positive lepromin reaction has raised the hopes that it may also prove effective against leprosy $\overrightarrow{0}$ (Lowe and McNulty, 1953); no evidence is yetavailable on this point. Vaccination of lepersw appears to have no effect on the course of the्s disease.

\section{Complications}

B.C.G. is at last being accepted for what it is a tubercle bacillus of very low virulence. Only in the two cases mentioned above has it beerpo reported as producing progressive tuberculosiso Lupus of the skin around the vaccination site has been reported in six cases (Marcusson, 1954) $\rightarrow$ Zammit-Tabona (1952) has described 17 cases o․ㅡ. phlyctenular conjunctivitis following B.C.G Apart from these, no new complications have besf reported. Le Melletier and Cassar (I95I) hase made a critical study of enlarged hilar shader following B.C.G. and have ennumerated causes.

Gaisford and Griffiths (1954) have made som interesting observations on the avoidance of glandular abscesses in infants. They have shown that there is a direct relationship between the dose and the incidence of abscesses. They haves also shown that in infants a glandular abscess is much commoner after vaccination on the leg than on the arm; this has been confirmed by our work. in the Oxford region. Any extra burden on the regional glands within six months of B.C.G? vaccination may produce a late glandular break down; vaccination should not therefore be given above the level of the insertion of the deltoid where the drainage is partly to the supraclaviculas glands, or the sudden load of an upper respiratore. infection on these glands may produce a break $\bar{N}$. down; for a similar reason no smallpox vaccinas tion or injection should be given in the same arnfु during this period. In view of this latter finding it would appear logical to make the use of the right arnat a standard procedure for all B.C.G. vaccinationso thus leaving the traditional injection arm free fo other inoculations.

\section{The Vole Vaccine}

Work on the vole vaccine has been progressing steadily over the last three years; a compact and 
comprehensive survey of the present position has been given by Wells and Wylie (1954). They have found that the vaccination of man or animals with vole vaccine by any of the standard routes gives rise to a higher and more lasting tuberculin sensitivity than with B.C.G. In guinea-pigs the resistance following vole vaccination outlasts the sensitivity, while after B.C.G. the resistance drops only a little slower than the allergy (Wells and Wylie, 1952). Hall and Wylie (1952) have demonstrated that the allergy in man seven weeks after vole vaccination is greater than after B.C.G. Animal experiments show that the higher level of sensitivity produced by the vole vaccine is accompanied by a higher level of resistance to tuberculous infection.

The incidence of lupus at the site of multiplepuncture vaccination is considerably higher than with B.C.G.; in view of the different virulence of these two organisms, this was to be expected. These ' lupoid reactions' had always been associated with secondary infection in low-grade mental deficients who had scratched their vaccinations with filthy hands (Wylie et al., 1954). Recently, however, Frew (1954) has reported cases in normal children; this has called a halt to multiplepuncture vole vaccination, pending the report of the M.R.C. trial. Meanwhile intracutaneous vole vaccination, which had been becoming increasingly popular, is being intensively studied.

\section{Future Policy}

The duration of allergy after vaccination has not yet been proved, but on the available evidence one must assume that roughly 80 per cent. of persons will still be positive at five years, after which the reversion rate may be high. To protect children only through their teens is not enough; some method of retesting young men and women of 18 to 20 years must be evolved. The only part of the Tuberculosis Service that has easy access to this age-group is the Mass Radiography Unit. As the incidence of the undiscovered case drops, there may come a time when the M.R.U. will no longer be an economic proposition. Would it not be a far-sighted policy for them to copy the Norwegian M.R.U.s and incorporate tuberculin testing and B.C.G. vaccination in their units ?

B.C.G. vaccination in the bush is impracticable without a reliable freeze-dried vaccine; active steps must be taken to solve the problem of standardization. Intensive research into concommitant vaccination and the possible protective effect of B.C.G. against leprosy must also be carried out.

Finally, should all infants be vaccinated at birth? This is a most difficult question to answer. On the one hand such a mass vaccination would largely eliminate tuberculous meningitis: on the other hand this is the age-group in which the greatest skill is required and in whichdespite the greatest skill-the incidence of glandular abscesses is highest. Lorber (1954) has shown what can be done without mass vaccination by the vigorous pursuit and vaccination of all infant contacts, which amount to only I per cent. of the total number of infants. Despite the difficulties, this is a question that cannot be shelved indefinitely.

\section{Summary}

A review is given of the main advances in B.C.G. and vole vaccination over the last three years. The extension of B.C.G. vaccination to school children has caused a demand for a simplification of procedure. In particular a 'one-shot' tuberculin test is a necessity; it is suggested that the Heaf multiple-puncture test may be the answer. The possibility of omitting conversion testing is discussed.

\section{BIBLIOGRAPHY}

BATES, L. E., et al. (195I), Pub. Health̀ Reports, Washington, $66,1427$.

BIRKHAUG, K. (1940), 'Iathergic Immunity in Experimental Tuberculosis,' John Griegs, Bergen.

CAPLIN, M., et al. (1954), Brit. med. F., ii, 895 .

COLES, H. M, T. (1952), Lancet, ii, 927.

DE ASSIS, A. (1953), Hospital, Rio de Faneiro, 44, 305.

DESPIERRES, G., et al. (195I), Rev. tuberc., 15, 45 I.

DICK, W. POINTON (1950), Brit. med.F., ii, r4I.

EDWARDS, L. B., and PALMER, C. E. (1953), ' B.C.G. Vaccination,' W.H.O. Monograph Series No. 12 , Geneva.

FINAL REPORT OF THE INTERNATIONAL TUBERCULOSIS CAMPAIGN (I95I), Copenhagen

FOLEY, H., and PARROT, L. (1953), Arch. Inst. Pasteur d'Algérie, 3I, 357 .

FREW, H. W. O., et al. (1953), Brit. F. Tuberc., 47, 68.

FREW, H. W. O. (1954), Tubercle, 35, 232.

GAISFORD, W. and GRIFFITHS, M. (1954), Tubercle, 35, 7.

GRIESBACH, R. (I954), 'Die BCG-Schutzimpfung,' Thieme, Stuttgart. (French translation by VAN DEINSE, F. (1954), 'La Vaccination par le.B.C.G.,' Flammarion, Paris).

HALL, I. MILLS and WYLIE, J. A. H. (1952), Lancet, ii, 608.

HAMMELBURG, EM. (r953), 'Ongewenste Reacties na BCGVaccinatie,' Kemink en Zoon N.V., Utrecht.

HEAF, F. (195I), Lancet, ii, I 5 I.

HEAF, F. (1953), Tubercle, 34, 335.

IRVINE, K. NEVILLE (1949), 'B.C.G. Vaccination in Theory and Practice,' Blackwell Scientific Publications, Oxford.

IRVINE, K. NEVILLE (1954), 'B.C.G. and Vole VaccinationA Practical Handbook,' Nat. Assn. Prev. Tuberc., London.

IRVINE, K. NEVILLE (I952), Postgrad. med. F., 28, 2 I 1 . IRVINE, K. NEVILLE (1955), Tubercle, 36, 2 I.

LE MELLETIER, J. and CASSAR, H. (I95I), Semaine Hóp., Paris, 27, 344.

LENDRUM, J. D. (1951), Brit. med. F., ii, 148.

LORBER, J. (1954), Э. Royal Sanitary Inst., 74, 99.

LOWE, J. and McNULTY, F. (1953), Leprosy Review, 24, 61.

MANDE, R. (1954), 'Manuel Practique de Vaccination par le B.C.G.,' Masson et Cie, Paris.

MARCUSSEN, P. V. (1954), Brit. F. derm., 66, 121 .

Bibliography continued on page 195. 


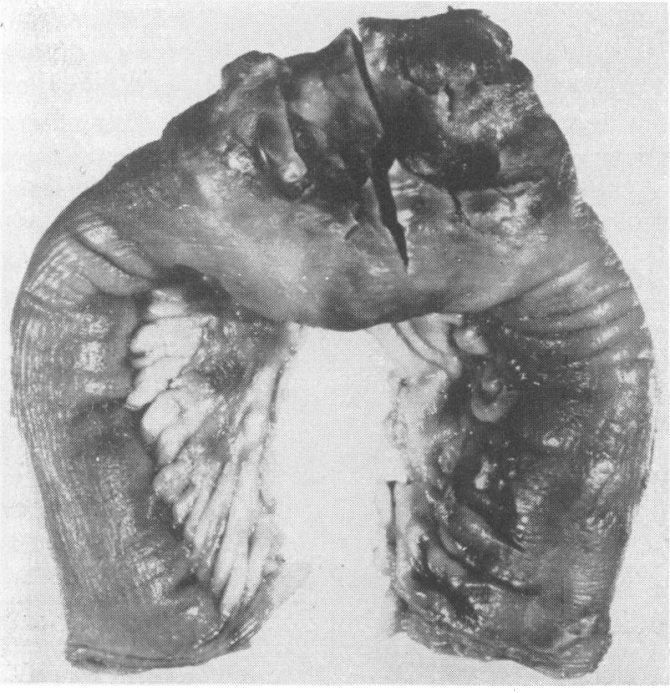

Excised portion of ileum with tumour at its centre.

any peritonitis during this period. Permission for post-mortem could not be obtained.

Pathological report on the specimen (Dr. J. W. Shackle) reads: 'This is a very cellular malignant tumour with many mitoses and some areas of necrosis. Apparently a reticulum-celled sarcoma.'

\section{Comment}

Wilkie (1953), who has thoroughly reviewed the available literature, reported a case in which perforations occurred on three occasions, but the total number of cases reported presenting with a perforation still appears to be less than 20. An exact figure is difficult to obtain because of the lack of differentiation between reticulum-celled sarcomas and lymphosarcomata. Frank, Miller and Bell (1942) review 36r cases of sarcoma of the small intestine and stress the rarity of perforation. They draw attention to a number of other case reports in which perforation occurred, but in at least one of these the growth was a lymphosarcoma. Lewis (1939), who collected six ٌ cases from the literature, added one of his own, $\vec{z}$ but this also was reported as a lymphosarcoma. $\stackrel{\perp}{\complement}$ Joergenson and Weibel (I95I), who review roo $ᄃ$ small intestinal tumours, do not mention reticu- $\overrightarrow{\vec{F}}$ lum-celled sarcoma as a separate entity. They do, however, stress the very poor prognosis of this condition. Hindmarsh (I95I) found II $\frac{\bar{O}}{\overline{0}}$ previous cases of perforated small intestinal sar- $\frac{\sigma}{\sigma}$ comata in the literature and added a further case, $\stackrel{\varnothing}{\varrho}$ but again this is reported as a lymphosarcoma. \& Recovery followed emergency laparotomy and $\vec{\circ}$ resection, which was followed by deep X-ray therapy. Williams and Fodden (1946) report an $\vec{\omega}$ unusual case of a reticulum-celled sarcoma causing $\frac{\Omega}{\circ}$ diverticulosis of the jejunum in a woman of 70 .

The case reported here is remarkable for certain features. No case in this advanced age-group $\stackrel{\omega}{\longrightarrow}$ appears to have been previously reported. As far as could be ascertained, the lesion was solitary $\perp$ without any ascertainable spread. The perforation $\vec{\infty}$ was of considerable size and yet it failed to give rise to any gross peritonitis. There is little doubt on histological grounds that the tumour here reported was a reticulum-cell sarcoma.

\section{Summary}

A further case of perforation of a reticulun 8 on celled sarcoma of the small intestine is reported The patient appears to have been considerab older than in any other previous report, and the lesion appears to have been solitary.

\section{Acknowledgments}

I am very grateful to Miss G. M. Barry for permission to publish this report, to $\mathrm{Dr}$. J. W. Shackle for the pathological report, and to Dr. L. W. Proger for the photograph.

\section{BIBLIOGRAPHY}

FRANK, L. W., MILLER, A. J., and BELL, J. C. (1942), Ann. Surg., I15, 544

HINDMARSH, F. D. (1951), Brit. med. F., ii, 1443

JOERGENSON, E. J., and WEIBEL, L. A. (I951), Calif. Med. 75, 395.

LEWIS, D. L. (1939), Brit. F. Surg., 26, 540.

WILKIE, D. (1953), Ibid., 4I, 50.

WILLIAMS, A. G., and FODDEN, J. H. (1946), Ibid., 34, 57.

Bubliography continued from page $187-K$. Neville Irvine, D.M.Oxon.

MEYER, J. (1954), Amer. Rev. Tuberc., 70, 402.

MINISTRY OF HEALTH (1953), Memo 324/BCG, p. 3.

OLSEN, H. C. (1953), Acta tuberc. Scand., 28 (1-2), I.

PIERCE, C. and DUBOS, RENE (1954), Tubercle, 35, 232.

REGISTRAR GENERAL'S STATISTICAL REVIEW (I949), 29, 27.

SAENZ, A., et al. (1954), Internat. tuberc. yearbook, 66.

SAMS, C. F. (1954), Amer. F. pub. health, 44, 903.

SEIBERT, F. B. and DUFOUR, E. H. (1954), Amer. rev. tuberc. 69, 585 .
THRAP-MEYER, H. (1954), Acta tuberc. Scand., 29 (3), 173.

VAN DEINSE, F. (1951), Amer. F. pub. health, 41, 1209.

WELLS, A. Q. and WYLIE, J. A. H. (1952), Brit. F. exper. Path., 33, 405 .

WELLS, A. Q. and WYLIE, J. A. H. (1954), Brit. med. bull., 10, 96. W.H.O. TECHNICAL REPORT SERIES No. 88 (1954).

WYLIE, J. A. H., et al. (1954), Thorax, 9, r9o.

ZAMMIT-TABONA, V. (1952), Brit. med. $\mathcal{f} .$, i, 837.

ZETTERGREN, L., et al. (1952), Svenska Läkartidningen, 49, 2936. 